\title{
A PROBLEMÁTICA AMBIENTAL E SEU AMBÍGUO ENCONTRO COM A LUTA PELA TERRA: DESAFIOS NA APROXIMAÇÃO ENTRE MODO DE VIDA TRADICIONAL E CONSERVAÇÃO DA NATUREZA
}

LA PROBLEMÁTICA AMBIENTAL Y SU AMBIGUO ENCUENTRO CON LA LUCHA POR LA TIERRA: DESAFÍOS EN EL ACERCAMIENTO ENTRE EL MODO DE VIDA TRADICIONAL Y LA CONSERVACIÓN DE LA NATURALEZA

\section{THE ENVIRONMENTAL ISSUE AND ITS AMBIGUOUS ENCOUNTER WITH THE STRUGGLE FOR LAND: CHALLENGES IN APPROACHING TRADITIONAL WAY OF LIFE AND NATURE CONSERVATION}

\section{Carina Inserra Bernini}

\begin{abstract}
Professora do Centro Universitário FIEO, Doutoranda do Programa de PósGraduação em Geografia Humana da Universidade de São Paulo.
\end{abstract}

\section{Resumo}

O presente artigo discute a apropriação do conceito de modo de vida tradicional nas recentes políticas de regulamentação de territórios tradicionais, resultados da luta pela terra de comunidades tradicionais camponesas. Para isso, retoma o surgimento da problemática ambiental no ocidente e o contexto que proporcionou a convergência da luta ambientalista com aquela das comunidades camponesas moradoras de áreas naturais. Em seguida, discute as dificuldades e conflitos em torno da apropriação do conceito de modo de vida tradicional camponês na formulação e regulamentação dos projetos de criação e re-criação de territórios tradicionais no âmbito das políticas de reforma agrária e de conservação ambiental. Percebeu-se uma tendência à idealização do conceito de tradição na formulação de tais projetos, expressão da desconsideração da dimensão simbólica dos modos de vida tradicional e da sua relação dialética com as novas situações ao longo da história.

Palavras-Chaves: comunidades tradicionais, modo de vida, conservação ambiental, reforma agrária.

\section{Resumen}

El presente artículo discute la apropiación de concepto de modo de vida tradicional en las recientes políticas de reglamentación de territorios tradicionales, resultantes de la lucha por la tierra de comunidades tradicionales campesinas. Para esto, retoma el surgimiento de la problemática ambiental en occidente y el contexto que proporcionó la convergencia de la lucha ambientalista con aquella de las comunidades campesinas residentes en áreas naturales. En seguida, discute las dificultades y conflictos en relación a la apropiación del concepto de modo de vida tradicional campesina en la formulación y reglamentación de los proyectos de creación y recreación de territorios tradicionales en el ámbito de las políticas de reforma agraria y de conservación ambiental. Nos dimos cuenta de una tendencia a la idealización del concepto de tradición en la formulación de dichos proyectos, expresión de la desconsideración de la dimensión simbólica de los modos de vida tradicional y de su relación dialéctica con las nuevas situaciones a lo largo de la historia.

Palabras clave: comunidades tradicionales, modo de vida, conservación ambiental, reforma agraria. 


\begin{abstract}
This article analyzes the use of the concept of traditional way of life by recent official policies which discriminates traditional territories in response to the mobilization of traditional peasant communities in the struggle for land. To do so, the article examines the emergence of the environmental problematic in the West and the context that enables the convergence of the environmental struggle with that of peasant communities dwelling in natural areas. Then it discusses the difficulties and conflicts related to the use of the concept of traditional peasant way of life in the formulation and implementation of projects of creation and re-creation of traditional territories under the policies of agrarian reform and environmental conservation. It concludes highlighting a leaning of idealization of the tradition concept in the formulation of such projects, which express the disregard of the symbolic dimension of traditional ways of life and their dialectics with new situations throughout history.
\end{abstract}

Keywords: traditional communities, way of life, environmental conservation, agrarian reform.

\title{
1. Do movimento ambientalista às ações de preservação ambiental
}

O crescimento da preocupação com a questão ambiental no mundo ocidental surge no pós-segunda guerra mundial, sobretudo na década de 1960, juntamente com outros movimentos sociais de contestação, especialmente os chamados movimentos da contracultura, movimento das mulheres, dos negros, e o movimento pacifista. O movimento ambientalista surge deste último, no contexto da guerra fria, e não se alia aos marcos daquele momento histórico. $\mathrm{O}$ movimento pacifista acreditava que nem o capitalismo nem o socialismo poderiam levar a humanidade a um futuro promissor, pois ambos se apoiavam em tecnologias de destruição nuclear. Ele ganha força nos EUA e na Alemanha quando do fracasso da guerra do Vietnã e a queda do Muro de Berlim. Se despregando dos marcos políticos da época, o movimento ambientalista conseguiu comunicar-se com toda humanidade, já que falava em nome do planeta. ${ }^{1}$

Ao escapar de uma apropriação ao estilo capitalismo ou socialismo, Leste ou Oeste, Estados Unidos ou União Soviética, ou burguesia ou proletariado, como costumavam a semantizar-se os conflitos naqueles marcos, surgiram novos sujeitos sociais, entre eles o movimento ambientalista. [...] O movimento ambientalista se mostrará extremadamente hábil para manejar novas formas de expressar-se politicamente, através dos meios de comunicação à distância. Falando

\footnotetext{
1 Poderíamos afirmar que há um caminho aberto, a partir daí, para uma tecnização do movimento ambientalista já que não necessariamente associará os modos de vida, as relações sociais, e a formação sócio-cultural, com o uso e destruição do meio ambiente.
} 
em nome da humanidade e do planeta contribuiu, como nenhum outro movimento, para a formação de uma nova comunidade de destino, para uma nova territorialidade, já não calcada no Estado nacional. (PORTO GONÇALVES, 2001, p. 67-68)

Enquanto movimento social bastante difuso - pois não há uma condição ecológica, não há uma base objetiva que o defina -, o movimento ambientalista irá impelir diversas e variadas bandeiras que se ligam com diversos e variados outros temas e lutas, desde a luta contra o desmatamento e a extinção de espécies, até aquela contra a construção de barragens, o uso de agrotóxicos e mesmo a diminuição de terras agricultáveis (PORTO GONÇALVES, 2008). E, nesse sentido, vem abarcando ao longo da história debates filosóficos e científicos de diversas naturezas e tendências ${ }^{2}$, muitas vezes contraditórias, pois são tributárias de visões sociais de mundo diferentes. Esses debates, que tratam, no limite, da relação sociedade-natureza, se colocam no campo de $\operatorname{lutas}^{3}$ da questão ambiental e, de acordo com o jogo de forças que vai se estabelecendo, determinadas visões vão se destacando como tendências e influenciando as resoluções político-jurídicas que regulam o uso dos diversos ambientes.

É possível afirmar que no Brasil a questão ambiental, no âmbito da $1 \mathrm{ei}^{4}$, foi influenciada inicialmente pelas concepções de preservação que estavam em voga nos EUA desde o século XIX. A idéia de preservar a natureza surgiu a princípio como resultado de uma preocupação por manter determinadas áreas intocadas frente ao desenvolvimento capitalista em marcha. Mas essa idéia de preservação não fazia a crítica à moderna relação sociedade-natureza já que mantinha certas áreas protegidas da destruição, visando pesquisas científicas futuras, e mesmo a criação de um "museu" natural para a contemplação da natureza "selvagem". Estava subjacente a essa idéia de preservação uma noção de natureza apartada do homem. Assim, para assegurar a natureza preservada, era necessário mantê-la sem qualquer uso direto da sociedade. Para Diegues (2004),

Tanto aqui [Brasil] como lá [EUA], o objetivo é conservar uma área "natural" contra os avanços da sociedade urbano-industrial, sem se atentar para o fato de grande parte dessas "áreas naturais" estarem

\footnotetext{
${ }^{2}$ Sobre as diversas escolas que pensam a relação sociedade-natureza e sua apropriação pelo movimento ambientalista ver DIEGUES, 2004.

${ }^{3}$ Referimos-nos a noção de campos de luta desenvolvida por Pierre Bourdieu (2007) para quem o campo é o universo relacional em que estão inseridos os agentes e as instituições que se relacionam em torno de questões sociais específicas.

${ }^{4}$ As primeiras leis visando a regulação do uso dos recursos naturais no país são de 1934: Código de Caça e Pesca, Código de Minas, Código de Águas e o Código Florestal.
} 
sendo habitadas por populações que nada têm de "modernas" e "tecnológicas". Ao contrário, em sua maioria são populações que vivem de atividades de subsistência, com fracas vinculações ao mercado e com pequena capacidade de alteração significativa dos ecossistemas. (p. 114)

O resultado objetivo desse movimento de preservação foi o processo de implantação de parques nacionais em todo o mundo como guardiões de uma vida selvagem. No Brasil, como em outros países chamados em desenvolvimento, a implantação dessas áreas, sobretudo a partir da década de 1950, chocou-se com territórios ocupados por comunidades camponesas tradicionais (agrícolas e extrativistas), o que trouxe para o centro do debate ambiental, mais claramente, o questionamento da possibilidade da convivência harmoniosa entre o homem e a natureza.

O estabelecimento de áreas protegidas no Brasil, sobretudo na Amazônia e na Mata Atlântica, a partir do governo militar, refletiu como mais um fator de desterritorialização das comunidades camponesas. Nos quatro cantos do país, os camponeses lutavam contra a expropriação resultante da expansão da infra-estrutura viária, dos projetos agropecuários, hidroelétricos, de mineração, e da especulação imobiliária gerada pela orientação desenvolvimentista daquele período. Uma expropriação e apropriação de terras públicas praticada pela elite agrária brasileira e incentivada pelo governo. Os conflitos de terra e os movimentos de resistência de posseiros e posteriormente de sem-terras multiplicavam-se pelo país, incentivados e organizados especialmente pela Comissão Pastoral da Terra, ligada à Igreja Católica e à Teologia da Libertação, e pelo Partido Comunista Brasileiro.

A destruição desenfreada que esse projeto desenvolvimentista proporcionava motivou, ao mesmo tempo, a reação dos ambientalistas para apressar o estabelecimento de áreas protegidas no anseio de salvar as áreas ainda preservadas.

Nesse cenário é que se intensificam os conflitos entre as comunidades tradicionais camponesas e as unidades de conservação da natureza, implantadas pelo governo. Mas intensificavam-se, também, os conflitos de terra entre camponeses, índios, grileiros e fazendeiros. Paulatinamente as comunidades tradicionais camponesas assim como os indígenas vão sendo impedidos de praticar o uso tradicional que faziam dos seus territórios ocupados historicamente. Desenham-se aí dois campos de lutas distintos, mas convergentes em certos momentos: o agrário e o ambiental. 


\section{A corrente conservacionista e o encontro com o modo de vida tradicional}

Como reação à visão radicalmente preservacionista que predominava na política ambiental brasileira até a década de 1980 e à desorganização e violência sofridas pelas comunidades dentro e no entorno de áreas protegidas, intensificam-se movimentos sociais e estudos sociológicos e antropológicos sobre comunidades, e a valorização dos modos de vida tradicionais. A etnociência, como ficou conhecida a corrente de estudos dos saberes, práticas e tecnologias das diversas culturas por todo mundo, chamou a atenção dos ambientalistas para a necessidade de considerar que existiam diversas noções de natureza e relações sociedade-natureza. Além disso, a valorização do etnoconhecimento permitiu que a conservação da natureza - motivação primeira dos ambientalistas, enquanto movimento - pudesse aparecer associada a essas práticas tradicionais.

Assim, abriu-se a possibilidade histórica da convergência entre a luta das comunidades tradicionais camponesas e aquela do movimento ambientalista, motivadas, entretanto, muitas vezes, por interesses e necessidades diferentes. Essas diferenças, portanto, dizem respeito, então, à natureza difusa do movimento ambientalista, que, como dissemos, comporta várias tendências; e ainda ao encontro dessas tendências com os interesses das comunidades que buscam a garantia da terra para a reprodução de suas famílias, influenciadas por um habitus, um modo de ser e de fazer de caráter tradicional, mas, ao mesmo tempo, sujeito a constantes transformações, resultantes, dentre outros fatores, da incorporação às suas práticas de algumas técnicas e aspirações modernas.

Reflexo e marco desse encontro, dessa convergência, é a luta dos seringueiros e dos povos da floresta na Amazônia. Apoiada internacionalmente por governos e organizações não-governamentais de caráter ambientalista, essa luta de comunidades extrativistas pelo direito de continuar ocupando a floresta e para isso mantê-la em pé, resultou na garantia de direitos legais de acesso à terra e à floresta com a formulação das reservas extrativistas.

A valorização dos saberes e modos de vida tradicionais aproximou as comunidades tradicionais camponesas da questão ambiental e, sobretudo, das políticas ambientais. A apropriação política da importância de seu modo de vida, principalmente por aquelas comunidades moradoras e vizinhas de áreas protegidas, tem sido um trunfo na luta pela permanência na terra. E essa permanência tem sido assegurada em muitos 
casos, então, por meio do reconhecimento da tradição, que se expressa por um conjunto de práticas e relações sociais melhor ajustadas aos ritmos naturais e mais próximas da natureza.

O jogo de forças no campo de lutas da questão ambiental, sobretudo a partir de meados da década de 1980, tem resultado numa configuração política em que a reivindicação do direito à diferença e a valorização desse diferencial como alternativa para uma convivência mais harmoniosa com a natureza têm sido levados em consideração na formulação de políticas públicas ambientais e agrárias. Daí surgiram novas unidades de conservação como as Reservas Extrativistas, as Reservas de Desenvolvimento Sustentável e a própria Política Nacional de Desenvolvimento Sustentável dos Povos e Comunidades Tradicionais, decreto de 2007. Também disputado dentro do campo de lutas ambiental e bandeira do ambientalismo social está, ainda, o direito à terra das comunidades remanescentes de quilombo, promulgado na Constituição de 1988.

No âmbito da política de reforma agrária, a aproximação entre luta pela terra, conservação ambiental e valorização de modos de vida tradicionais, também resultou em modalidades de assentamentos diferenciados como os Projetos de Assentamentos Agroextrativistas (PAEs), Projetos de Assentamentos Florestais (PFs) e os Projetos de Desenvolvimento Sustentável (PDSs). Trata-se de tipos de assentamentos direcionados às comunidades que vivem do extrativismo e da agricultura de subsistência, em áreas em que a cobertura vegetal nativa encontra-se significativamente preservada. Nesses assentamentos e nas unidades de conservação que admitem o uso agro-extrativista valoriza-se a conservação da biodiversidade dos domínios brasileiros a partir do apoio às práticas tradicionais de produção.

Entretanto, a valorização das diferenças constitutivas das comunidades tradicionais aparece em instrumentos político-jurídicos relacionada à noção de patrimônio cultural. Veremos que essa orientação, inspirada em uma noção de cultura cuja ênfase recai sobre os aspectos da memória e da herança cultural, é uma das sementes dos conflitos que surgem depois, quando do enquadramento destas comunidades às diretrizes conservacionistas gerais. 


\section{O encontro entre direito à terra e conservação ambiental: desafios da}

\section{apropriação do conceito de modo de vida tradicional}

A regulamentação do uso da terra nos assentamentos e unidades de conservação que admitem uma parceria entre conservação ambiental e modo de vida tradicional coloca novos desafios e conflitos. As discussões que baseiam o zoneamento dessas áreas opõem, frequentemente, Estado, ONG's e comunidades tradicionais no que diz respeito às práticas agro-extrativistas e às técnicas agrícolas recomendadas para essas áreas. Um indicativo para a definição do uso do solo nesses territórios tem sido a adoção das técnicas agroecológicas para a prática da agricultura de base familiar.

Entretanto, é recorrente a dificuldade de aceitação e adoção dessas técnicas por parte de comunidades camponesas. A maior parte das discordâncias se concentra em torno da proibição do corte da vegetação para a prática da agricultura, assim como a proibição do uso de determinados defensivos químicos. Os camponeses, muitas vezes, defendem que o cultivo sob a mata não apresenta resultados favoráveis, crítica que indica a percepção que vêm tendo sobre as técnicas chamadas de agroflorestais.

Esse conflito em torno da adoção das técnicas agroecológicas nos permite situar aquilo que vem sendo entendido, no âmbito das políticas agrárias e ambientais, como tradicional.

Em boa parte dos bairros rurais da região de Mata Atlântica do estado de São Paulo, por exemplo, a referência das comunidades em relação às técnicas de cultivo tradicionais se remete à prática da coivara associada a um sistema de rotação de terras. O sistema de cultivo empregado tradicionalmente utiliza o corte e a queimada da vegetação para o cultivo de mandioca, feijão, milho, arroz etc., e posterior pousio para a retomada da fertilidade do solo. Essa técnica foi herdada dos índios de matriz tupi por grande parte das comunidades caboclas no Brasil. A sua prática, segundo alguns pesquisadores, garantia, a fertilidade do solo e ao mesmo tempo a conservação das florestas, como afirma SILVA (2008, p. 213-215):

Este sistema de cultivo, que a princípio parece rudimentar e agressivo ao meio ambiente, adequava-se perfeitamente às condições físicas e culturais do bairro [referência ao bairro do Mandira, Cananéia-SP], pois como a terra era de uso coletivo o rodízio de terras estava dentro de seus quadros de valores. Além do mais, freqüentes chuvas ocasionavam um rápido lixiviamento do solo já arenoso e pouco fértil, para ser cultivado com sucesso necessitava da nutrição conseguida pela queima de matéria orgânica (a coivara). Atualmente, há pesquisas 
acerca dos efeitos benéficos da agricultura de rotação de terras em áreas florestais. Pesquisadores como Diegues (1994); Balée (1994 e 1998); Goméz-Pompa (1971 e 2000) e Posey (1987, 1989 e 2000) dizem que a manutenção e o possível aumento da biodiversidade em florestas tropicais está relacionada com as práticas tradicionais da agricultura itinerante, pois o sistema regenerativo da floresta úmida parece estar muito bem adaptado às atividades das populações tradicionais.

A prática e a eficácia da rotação de terras foram ficando cada vez mais limitadas na medida em que o acesso livre à terra se tronava mais difícil em decorrência do avanço da agricultura capitalista, sobretudo a partir da década de 1960, nos territórios ocupados por comunidades camponesas, praticantes de uma agricultura familiar. As restrições ambientais resultantes da política ambiental também podem ser entendidas como fatores decisivos para a dificuldade do emprego da coivara como técnica agrícola.

Essas limitações levaram a modificações nas relações sociais de produção dessas comunidades camponesas, e, ao mesmo tempo, nas técnicas agrícolas tradicionalmente utilizadas por elas. A quantidade restrita de terra, a proibição da queimada, a inviabilidade da rotação de terras e o avanço da agricultura capitalista contribuem para a diminuição da diversidade da produção, na medida em que a menor disponibilidade de terra compromete a fertilidade do solo, que passa a ser usado sem o necessário descanso, além do fato de os gêneros tradicionalmente cultivados começarem a perder espaço para as culturas comerciais. Esse gênero comercial geralmente é produzido com técnicas que compõem o pacote tecnológico "moderno".

Entretanto, é necessário analisar essas transformações de maneira abrangente e de forma dialética, percebendo que as mudanças no modo de uso da terra não acontecem de forma a apagar completamente os saberes tradicionais. Primeiro porque as técnicas modernas (hoje chamadas de convencionais) são dispendiosas (no sentido financeiro e prático) para os camponeses e, por isso, são por eles selecionadas e empregadas conforme sua necessidade, e segundo porque essas novas demandas e técnicas se fundem com os saberes adquiridos no contexto produtivo anterior.

O descompasso entre o modo de vida tradicional das comunidades camponesas da Mata Atlântica e as noções de tradição e de desenvolvimento de comunidades tradicionais que norteiam as ações da política ambiental e de reforma agrária do Estado, nos convida a uma reflexão acerca das noções de campesinato, comunidade e modo de vida tradicional desenvolvidas pela academia, e dos diferentes significados atribuídos a 
este último pelos atores atuantes nos campos de luta ambiental e agrário. Também é importante refletir sobre a apropriação dessas noções no jogo político no campo da reforma agrária.

A construção teórica do conceito de modo de vida camponês na Sociologia, na Antropologia e na Geografia está intimamente relacionada à noção de tradição e de comunidade. Na Geografia podemos elencar Paul Vidal de La Blache como um dos primeiros geógrafos que contribuíram, de alguma forma, para a construção do conceito. Na sua trajetória, La Blache, ao longo da segunda metade do século XIX, se dedicou ao estudo de comunidades rurais, especialmente na França, na busca da compreensão da unidade entre os aspectos físicos e humanos que conformavam cada uma das diversas paisagens daquele país. Para isso definiu e utilizou o conceito de gênero de vida, ou seja, o resultado das influências físicas, históricas e sociais presentes na relação do homem com o meio. (LENCIONE, 2003)

Antônio Candido (1964), na Sociologia, definiu a sociedade caipira como sendo aquela quase fechada, com uma economia de subsistência, utilizando técnicas de cultivo que "permitiram estabilizar a relação do grupo com o meio". Para Candido, as relações de vizinhança e parentesco são fundamentais para a manutenção dessa economia e são esses laços de solidariedade que nos permitem identificar uma comunidade, um bairro rural.

Esta [o bairro] é uma estrutura fundamental da sociabilidade caipira, consistindo no agrupamento de algumas ou muitas famílias, mais ou menos vinculadas pelo sentimento de localidade, pela convivência, pelas práticas de auxílio mútuo e pelas atividades lúdico-religiosas. (CANDIDO, 1964, p.81)

A idéia de sociedade caipira de Candido equivale à expressão de um tipo específico de gênero de vida de La Blache, entretanto, enquanto Candido desenvolve a sua abordagem com base numa perspectiva dialética - já que se preocupa em refletir sobre as relações do caipira com a sociedade mais ampla e as mudanças em seu modo de vida -, La Blache utiliza uma perspectiva historicista, uma vez que está preocupado em definir as particularidades da relação entre o homem e o meio em cada região por ele delimitada.

Maria Isaura Pereira de Queiroz (1973) também contribuiu significativamente para a compreensão do modo de vida camponês e concordou com Candido na definição 
do campesinato como uma sociedade quase fechada. Para Queiroz, o camponês se caracteriza por ser aquele que vive do que produz diretamente, utilizando para troca ou para venda aquilo que não emprega no consumo diário.

Apesar da grande importância atribuída ao cultivo para o auto-consumo e às relações de parentesco e vizinhança, ambos os autores fazem referência ao contato do campesinato com outras classes. A noção clássica de campesinato contém, assim, a dimensão da sua subordinação, de certa forma, a essas classes e mesmo ao Estado:

Estabelecia-se uma rede estreita de relações entre os roceiros
pertencentes ao mesmo grupo de vizinhança, que adquiriam
consciência da unidade e do funcionamento deste. Configuração social
intermediária entre a família, de um lado, e de outro o arraial, ou a
vila, ou a cidadezinha, o bairro apresentava as formas mais
elementares de sociabilidade da vida rústica, que se alargavam em
diferentes graus a partir dele, na seguinte escala: a) relações
familiares; b) relações de vizinhança; c) relações dos bairros entre si;
d) relações com a região; e) relações com o exterior (isto é, com tudo
que ultrapasse a região). Tal gradação indica que os bairros,
constituindo embora unidades funcionais relativamente autônomas,
eram sempre tributários de um povoado ou de uma cidadezinha.
(QUEIROZ, 1973, p.4, grifo nosso)

Os estudos e pesquisas realizados por Queiroz e Candido já indicavam que esses camponeses, moradores dos bairros rurais paulistas (focos de suas pesquisas), estavam inseridos e participavam de um contexto de transformação. Naquele momento histórico, o país passava por uma intensa urbanização, especialmente o estado de São Paulo, e havia a preocupação da Sociologia Rural e da Geografia Agrária em pesquisar quem eram e como viviam esses camponeses (caipiras, caiçaras, caboclos etc.) que estavam sofrendo com esse processo (perda de terras para a especulação imobiliária, para a agricultura comercial capitalista etc.). Neste contexto, estes sujeitos eram compreendidos como representantes de um passado que seria superado pela modernização da agricultura e o avanço da tecnologia e das relações capitalistas.

Na geografia, Pasquale Petrone (1961) estudou o Vale do Ribeira na década de 1950 também com o objetivo de compreender o desenvolvimento desta região dentro do estado de São Paulo e analisou as transformações que a baixada passava frente à valorização das terras, as melhorias dos sistemas de transporte e as modificações nos sistemas agrícolas tradicionais. Nessa obra, como em outros dos seus estudos, contribuiu para o entendimento dos modos de vida dos camponeses estudados, 
sobretudo pela sistematização dos sistemas agrícolas praticados pelos diferentes "tipos humanos" por ele classificados.

A compreensão desses sujeitos foi de fundamental importância, especialmente a sistematização de seus saberes, da estrutura e funcionamento dessas sociedades rurais e suas tradições. Entretanto, se faz necessário também perceber esses camponeses como sujeitos sociais que, inseridos no fluxo ininterrupto da história, têm seus saberes incorporados - habitus (BOURDIEU, 2007): modo de pensar, de agir, valores dos indivíduos incorporados com o passar do tempo, ao longo de gerações, a partir da sua sociabilização naquele grupo - continuamente transformados e re-significados na medida em que se relacionam nos campos de luta no qual vão se inserindo e sendo inseridos. Aspecto que já nos sugerem as análises dos autores clássicos.

Os acontecimentos, ao longo da história, nos campos de lutas agrário e ambiental (e outros como o econômico e mesmo aquele definido em torno do espaço urbano) trazem novas questões e novas preocupações, como é o caso da conservação ambiental, a ponto de aquilo que antes era visto como atraso - o modo de vida tradicional - ser considerado como algo excepcional e que deve ser valorizado.

Desse modo, a construção das recentes políticas de acesso a terra baseadas na idéia de que é preciso preservar a mata e o "patrimônio cultural" representado pelo modo de vida destas comunidades, é fruto de posições assumidas por esses sujeitos camponeses (caiçaras, quilombolas etc.) na interação com um conjunto de outros sujeitos no campo de lutas ambiental e da reforma agrária. Ou seja, é fruto de como o habitus desses sujeitos foi sendo recriado e mobilizado a partir das posições que eles foram tomando no jogo de forças que foi se desenhando ao longo da história.

A interação com esses diversos atores sociais diante das situações colocadas sobretudo aquelas que ameaçam diretamente seus territórios - proporcionou condições para a reivindicação da identidade de comunidade tradicional. De um lado, pela reação diante da visão preservacionista de que para assegurar os ecossistemas naturais é preciso manter áreas sem moradores; e, de outro, pela associação com uma visão social e ecológica que reconhece a existência de culturas tradicionais e sua importância na conservação da natureza.

Essa visão ecológica e social se torna forte no Brasil principalmente a partir de meados dos 1980 e, segundo Diegues (2004), tem grande influência do ecologismo 
social e do ecomarxismo, escolas de pensamento ecológico que associam a degradação ambiental com os imperativos do capitalismo. E são as análises, pesquisas e a militância de boa parte dos pesquisadores ligados a essas correntes, articulados com os movimentos sociais das comunidades tradicionais, que vão influenciar o debate ambientalista e resultar nas políticas públicas direcionadas às comunidades tradicionais. Os termos da PNPCT (decreto 6040, de 2007), por exemplo, demonstram forte colaboração da construção teórica desenvolvida por estes pesquisadores, sobretudo na definição do que são populações tradicionais e territórios tradicionais:

Art. $3^{\circ}$ Para os fins deste Decreto e do seu Anexo compreende-se por:

I - Povos e Comunidades Tradicionais: grupos culturalmente diferenciados e que se reconhecem como tais, que possuem formas próprias de organização social, que ocupam e usam territórios e recursos naturais como condição para sua reprodução cultural, social, religiosa, ancestral e econômica, utilizando conhecimentos, inovações e práticas gerados e transmitidos pela tradição;

II - Territórios Tradicionais: os espaços necessários a reprodução cultural, social e econômica dos povos e comunidades tradicionais, sejam eles utilizados de forma permanente ou temporária, observado, no que diz respeito aos povos indígenas e quilombolas, respectivamente, o que dispõem os arts. 231 da Constituição e 68 do Ato das Disposições Constitucionais Transitórias e demais regulamentações. (BRASIL, 2007)

A conceituação ampla de povos e comunidades tradicionais sugere o entendimento da tradição a partir de suas múltiplas dimensões, além de possibilitar a interpretação de que a forma objetiva de uso dos recursos naturais está intimamente associada aos símbolos, mitos e saberes acumulados e re-interpretados pelas gerações. $\mathrm{O}$ aspecto multidimensional que envolve as culturas tradicionais foi ressaltado por Diegues (2004):

Um aspecto relevante na definição de culturas tradicionais é a existência de sistemas de manejo dos recursos naturais marcados pelo respeito aos ciclos naturais, à sua exploração dentro da capacidade de recuperação das espécies de animais e plantas utilizadas. Esses sistemas tradicionais de manejo não são somente formas de exploração econômica dos recursos naturais mas revelam a existência de um complexo de conhecimentos adquiridos pela tradição herdada dos mais velhos, de mitos e símbolos que levam à manutenção e ao uso sustentado dos ecossistemas naturais. (p. 84-85) 
Diegues, assim como os autores clássicos, também admite a relação de dependência e subordinação das comunidades tradicionais em relação à sociedade urbano-industrial e fornece pistas do caráter dialético desta relação:

As culturas tradicionais decorrentes da pequena produção mercantil não se encontram no entanto isoladas no Brasil de hoje, mas articuladas com o modo de produção capitalista (Diegues, 1983; 1992c). Esta maior ou menor dependência do modo de produção capitalista, por outro lado, tem levado a maior ou menor desorganização das formas pelas quais o pequeno produtor trata $o$ mundo natural e seus recursos. [...] [porém] nem sempre a maior articulação com o modo de produção capitalista tem levado à destruição da pequena produção mercantil. Ao contrário, como sucede freqüentemente no caso da pesca artesanal, o modo de produção capitalista se apropria da produção artesanal, sem necessariamente desorganizar esse modo de produção e reprodução social. (DIEGUES, 2004, p. 94)

Assim, Diegues também contribui para que entendamos que a tradição incorporada e reproduzida pelas comunidades tradicionais camponesas está relacionada aos jogos de forças e às transformações que os grupos vão sofrendo ao longo da história.

Ainda que as recentes políticas públicas que buscam a valorização das comunidades tradicionais tenham sofrido influência de autores como Diegues e outros ${ }^{5}$, a execução de projetos e ações com este caráter traz à tona novas contradições, que revelam a prevalência de um entendimento reducionista da noção de tradição, bem como as dificuldades que cercam a relação entre um modo de vida tradicional e a concepção de sustentabilidade adotada pelas instituições envolvidas.

O movimento de valorização da diferença, da tradição, parece resultar, em certos casos, no descolamento da tradição do movimento da história. Nesse sentido, prevalece um conceito idealizado de tradição, de comunidade camponesa, o que pode implicar fortes contradições e restrições para a reprodução desses camponeses e para a construção da sua territorialidade.

Em relação ao estranhamento das comunidades tradicionais da Mata Atlântica no que diz respeito à proibição do corte da mata para o plantio e ao estímulo ao cultivo de gêneros para alimentação das famílias sob a mata, é possível perceber que aquilo que

\footnotetext{
${ }^{5}$ Associados a escolas da Antropologia voltadas ao entendimento dos modos de vida tradicional podemos incluir uma série de pesquisadores, com destaque para aqueles ligados ao Núcleo de Apoio a Pesquisa sobre Populações em Áreas Úmidas Brasileiras (NUPAUB).
} 
a política pública definiu como prática sustentável não coincide com práticas tradicionais das comunidades camponesas e não leva em conta o habitus desses sujeitos.

Assim, se em algum momento o reconhecimento da tradição dessas comunidades foi decisivo para a garantia do seu direito de permanência na terra, a implantação e a realização das medidas que regulamentam este direito para comunidades vizinhas e/ou moradoras de áreas florestadas, parece supor a necessidade de superação da tradição incorporada (em nome da sustentabilidade, que passa a ser concebida em referência a uma racionalidade de base técnico-científica e não tradicional). Os agentes do Estado têm um registro do tradicional que remete àquelas comunidades que produzem seus meios de vida a partir de uma relação mais próxima com a natureza e que, portanto, se ajustam com a necessidade de conservação da natureza. Entretanto, esse entendimento da vida a partir de um tempo mais lento, baseado nos ciclos naturais, não se expressa apenas nas formas objetivas que assumem as práticas dessas comunidades. Os usos têm significados e estes são subjetivos. Propostos como principais componentes constitutivos do sistema de produção a serem adotados nos territórios tradicionais agora mediados pela política ambiental (assentamentos e unidades de conservação) a agroecologia e o manejo de espécies florestais, não aparecem como parte dos saberes e dos valores das comunidades tradicionais, dificultando a aceitação e a prática das novas técnicas.

Contraditoriamente, a permanência na terra que foi legitimada pelo modo de vida tradicional dessas comunidades passa a depender, para a sua efetivação, da modificação de tais práticas e de seu ajuste aos imperativos de sustentabilidade definidos a partir de uma racionalidade que lhes é estranha, em nome da necessidade de conservação dos recursos naturais.

Esse desacerto pode estar relacionado também com a própria interpretação dos instrumentos jurídicos que estão na origem da discussão do reconhecimento de direitos às comunidades tradicionais. Investigando os termos explicitados na Constituição Brasileira, observamos a existência de um viés que privilegia os aspectos de permanência da cultura. O seu artigo $216^{6}$ define quais são os bens do patrimônio

\footnotetext{
${ }^{6}$ Art. 216. Constituem patrimônio cultural brasileiro os bens de natureza material e imaterial, tomados individualmente ou em conjunto, portadores de referência à identidade, à ação, à memória dos diferentes grupos formadores da sociedade brasileira, nos quais se incluem: I - as formas de expressão; II - os modos de criar, fazer e viver; III - as criações científicas, artísticas e tecnológicas; IV - as obras, objetos, documentos, edificações e demais espaços destinados às manifestações artístico-culturais; V - os
} 
cultural brasileiro, incluindo entre eles, os modos de criar, fazer e viver dos grupos formadores da sociedade nacional. Trata ainda da obrigação do poder público pela preservação desse patrimônio. O uso dos termos memória, patrimônio e preservação sugere o domínio de uma perspectiva histórico-linear no tratamento das diferentes manifestações culturais brasileiras e suas formas de territorialização. A diferença cultural é entendida como uma herança do passado. Aquele que é diferente tende a ser classificado a partir da definição de sua posição em uma escala de tempo, sendo o espaço por ele produzido freqüentemente entendido como expressão de um tempo passado. E a garantia da cidadania (o acesso aos direitos básicos - educação, moradia, saúde etc.), paradoxalmente, passa a ser vinculada ao reconhecimento dessa tradição.

As dificuldades de aceitação e de entendimento da proposta de agricultura indicada para os territórios de comunidades tradicionais nos revelam outros aspectos relacionados à complexidade que envolve a reprodução desses camponeses no período histórico em que vivemos, marcado pela emergência política de identidades étnicas, mas também pelo avanço do neoliberalismo, da globalização.

Brandenburg (2002) chama a atenção para o fato de que os sistemas agroecológicos, na sua origem, estão baseados numa relação homem-natureza em que existe uma preocupação com o equilíbrio e a preservação não apenas no sentido ecológico, mas também humano. Para ele, a diversidade de atividades agrícolas e pecuárias leva a uma relativa autonomia do agricultor. São esses princípios (liberdade e autonomia no trabalho, diversidade da produção etc.) que convergem para os sistemas tradicionais do campesinato.

No entanto, é comum os camponeses identificarem os técnicos agrícolas como fiscalizadores e cerceadores da sua liberdade no trabalho. Ao mesmo tempo, apresentam dificuldade de entender a produção agroecológica como veículo dessa autonomia. Ora, mas, a princípio (como sugere Brandenburg), a agroecologia não contribuiria para uma autonomia na organização do trabalho do agricultor?

Essa contradição nos leva a considerar as diferentes espaço-temporalidades que sugere a avaliação e análise de projetos que pretendem conciliar comunidades tradicionais camponesas e conservação ambiental. Encontram-se na realização destes

conjuntos urbanos e sítios de valor histórico, paisagístico, artístico, arqueológico, paleontológico, ecológico e científico. $\S 1^{\circ} \mathrm{O}$ poder público, com a colaboração da comunidade, promoverá e protegerá o patrimônio cultural brasileiro, por meio de inventários, registros, vigilância, tombamento e desapropriação, e de outras formas de acautelamento e preservação. 
projetos, diversos atores sociais motivados por diferentes interesses, necessidades e expectativas.

Misturam-se os discursos técnico-científicos - que discutem a viabilidade ecológica, econômica, social dos projetos e que possuem lógicas e conjuntos de significados próprios - com as leis ambientais que procuraram dar materialidade às negociações políticas que resultaram da luta nos campos da reforma agrária e do ambientalismo.

Segundo Brandenburg, é possível identificar um "movimento agroecológico" que foca sua crítica no domínio da lógica industrial na agricultura. Mas, por outro lado, dentro da agroecologia, é comum incluírem-se diversas técnicas e sistemas de produção que vão desde a agricultura biodinâmica, orgânica e efetivamente ecológica.

Além disso, o mesmo autor sugere que os posicionamentos políticos, que demonstram a visão de mundo que está por traz daqueles que praticam essas diversas técnicas, não necessariamente convergem. Até porque, as origens e formações (técnicoacadêmicas, políticas etc.) dos profissionais e dos agricultores que incentivam e se engajam na propagação dessa agricultura "alternativa" são diversas.

O agricultor agroecológico não constitui uma categoria social homogênea. Isto significa dizer que, tanto no Brasil quanto na Europa, a agricultura ecológica não constitui uma estratégia de reprodução de uma categoria social específica, não podendo ser considerada como uma solução para as questões relacionadas à sobrevivência e reprodução de uma determinada categoria. (BRANDEMBURG, 2002, p. 14)

Concordamos com esse ponto de vista na medida em que não é possível assumir a agricultura ecológica como um conjunto de técnicas que será o grande diferencial para o sucesso de projetos que aproximam conservação ambiental e o uso tradicional da terra. Mas, consideramos que, ao ser re-significada pelos sujeitos, a agroecologia poderá sim, a longo prazo, constituir uma mudança na forma de se relacionarem e se apropriarem do seu território. E, nesse sentido, contribuir como estratégia de reprodução do campesinato, sobretudo nas situações em que as comunidades estão dentro ou no entorno de áreas naturais protegidas.

A rejeição às práticas agroecológicas por parte dos camponeses não ocorre, então, simplesmente porque são práticas modernas, portanto diferentes das tradicionais/convencionais, mas sobretudo porque é necessário um tempo para que tais 
práticas sejam adaptadas e resignificadas em relação aos saberes e práticas do grupo. E esse tempo não corresponde àqueles das lideranças, dos técnicos do Estado ou das ONG's, os quais trabalham com metas e objetivos a serem alcançados num prazo estabelecido de acordo com outros interesses e necessidades.

Prevalecem entre esses diversos atores diferentes espaço-temporalidades relacionadas a diferentes racionalidades e maneiras de situar o homem no espaçotempo. É recorrente no Estado a perspectiva "desenvolvimentista", a concepção do tempo de forma linear e do espaço de forma abstrata, de maneira que a mudança aparece vinculada à idéia de progresso. A perspectiva tradicional camponesa que orienta a comunidade é permeada pela idéia de reprodução da vida num espaço pleno de conteúdos e num tempo cíclico marcado pelos ritmos da natureza, que é também um tempo lento, em que as mudanças costumam levar, assim, um maior tempo para serem assimiladas.

A resistência às técnicas "novas" demonstra uma dificuldade dos camponeses em apreender a lógica dos projetos. Essa lógica que tem como meta primordial a conservação ambiental combinada com o desenvolvimento econômico, pressupõe um planejamento, baseado numa racionalidade econômico-ecológica (visando ganhos econômicos e ambientais), que prevê objetivos e resultados que serão alcançados num futuro de médio e longo prazos.

A prática do planejamento supõe a construção do futuro pelo cálculo e uma vez construído, pressupõe uma abstração, um desenho de algo novo. É o que Bourdieu chama de Planificação Racional. Diferentemente, para o campesinato o futuro é percebido diretamente no presente imediato, ou seja, por meio das experiências acumuladas que constituem, nesse sentido, a própria a tradição. (BOURDIEU, 1979)

Assim, tradicionalmente os camponeses investem naquilo que confiam que terão retorno para o provimento das necessidades da sua família. Se durante algumas décadas aprenderam que o cultivo com o uso de agrotóxico garantia o mínimo para a reprodução de suas vidas, o retorno (retorno porque, num passado relativamente recente, não utilizavam insumos químicos) a uma técnica que utiliza mais elementos orgânicos e/ou ecológicos não será imediatamente assimilado.

Primeiro porque não é, em geral, a motivação preservacionista/conservacionista da natureza que sensibiliza esses sujeitos para que embarquem em novos 
"investimentos". E tampouco a crença numa possibilidade futura de maior renda que a adoção dessas técnicas poderá gerar. A tendência é que incorporem determinadas modificações no seu fazer agrícola na medida em que essas técnicas se revelem capazes de garantir a reprodução das suas famílias em condições favoráveis. Seu investimento no novo ocorre geralmente quando confirmam, na prática, a eficácia dessas técnicas para assegurar as necessidades da família. Além disso, a adoção desse "novo" e o entendimento da necessidade de conservação irão acontecer quando essas técnicas fizerem sentido em relação ao conjunto de práticas, valores e vivências que o grupo possui.

Contudo, isso não quer dizer que, para reproduzirem a família, comprometeriam necessariamente todos os aspectos ecológicos (a mata, as águas, o solo) dos seus lotes, mas que a preocupação com a conservação possivelmente faz e fará mais sentido se e quando relacionada a essa necessidade primeira de assegurar a reprodução da própria família.

Cabe aqui uma reflexão sobre o que faz um modo de vida poder ser chamado de tradicional. O objetivo de reproduzir a família não significa, entretanto, que os camponeses não queiram ter mais bens, melhores condições para seus filhos etc. Mas, ao mesmo tempo, o possível acúmulo de bens não significa, por fim, abraçar a ideologia capitalista (do lucro). O fato de o objetivo da produção ser a reprodução da família e não o lucro e a acumulação, implica uma outra forma de se relacionar com a natureza e com sua apropriação e uso, mediada por outros valores. Da mesma forma, o fato de constituírem um saber próprio, fundamentado na prática, também contribui para uma postura de constante desconfiança e resistência em relação às mudanças em geral sugeridas por atores externos ao seu modo de vida, e aos possíveis riscos que elas representam. Ou seja, o ser tradicional representa, sobretudo, o fato de o seu modo de vida reproduzir-se mais em conformidade com os ritmos cíclicos da natureza e possuir um tempo mais lento, em que as transformações, embora estejam presentes, não apresentam a mesma intensidade e aceleração que caracteriza a sociedade moderna capitalista. Mesmo assim, tudo isso não impede que esses sujeitos sociais vivenciem momentos de ambigüidade em face dos atrativos do mundo da mercadoria.

Além disso, a realização de mudanças nas práticas agrícolas e extrativistas das comunidades entendidas como tradicionais se relaciona, por sua vez, com outras escalas de atuação do próprio Estado, agentes econômicos diversos, dentre outros, nos campos 
de lutas ambiental, econômico e agrário. E, por isso, a eficácia dos objetivos e metas de projetos de assentamento e UC's também depende do alcance de processos e políticas que se desdobram em escalas mais amplas. O sucesso da prática agroecológica, por exemplo, está atrelado às políticas econômicas e agrárias para facilitar o escoamento e a colocação no mercado dos produtos orgânicos, oriundos de SAF's. Até então, poucas são as políticas públicas para garantia do escoamento da produção familiar no Brasil $^{7} \mathrm{e}$ dentro delas, menos importância ainda se verifica em relação à qualidade das técnicas empregadas pelos camponeses.

\section{Considerações Finais}

Percebemos o avanço político (porém que revela novas contradições) concernente às políticas especiais para as comunidades tradicionais, especialmente a Política Nacional dos Povos e Comunidades Tradicionais (PNPCT, decreto 6040 de 2007) que reconhece o que são comunidades tradicionais, busca a garantia dos seus territórios e o cumprimento dos direitos básicos a essas comunidades. Entretanto percebemos a complexidade que envolve a realização desses direitos na sociedade moderna capitalista.

A questão da tradição é transformada em fundamento para definições legais, e para a garantia de direitos, no campo jurídico, que está estruturado com base em princípios da sociedade moderna, que se funda na idéia de universalidade e no direito do indivíduo (fundamentos do direito positivo). O modo de vida tradicional é, então, situado numa escala temporal linear e entendido como parte de um tempo histórico passado. Assim, esse diferente terá direito a permanecer identificado com suas

\footnotetext{
${ }^{7}$ Podemos citar alguns avanços representados pelo Programa de Aquisição de Alimentos (PAA), do Ministério da Agricultura. "O Programa de Aquisição de Alimentos - PAA foi instituído pelo artigo 19 da Lei n. ${ }^{\circ} 10.696$ de 2 de julho de 2003 e regulamentado pelo Decreto ${ }^{\circ} 6.447$, de 07/05/2008. Dentre seus objetivos destacam-se a geração de renda e sustentação de preços aos agricultores familiares, o fortalecimento do associativismo e do cooperativismo, o acesso a uma alimentação diversificada para uma população em insegurança alimentar e nutricional. O Programa valoriza a produção e a cultura alimentar das populações, dinamizando a economia local, a formação de estoques estratégicos, a melhoria da qualidade dos produtos da agricultura familiar, o incentivo ao manejo agroecológico dos sistemas produtivos e ao resgate e preservação da biodiversidade.O PAA é voltado para agricultores familiares enquadrados no Programa de Fortalecimento da Agricultura Familiar (PRONAF), assim como Povos e Comunidades Tradicionais qualificados de acordo com o Decreto n. ${ }^{\circ}$ 6.040, de 07/02/2007 - extrativistas, quilombolas, famílias atingidas por barragens, trabalhadores rurais sem terra acampados (definidos de acordo com a Portaria MDA n. ${ }^{\circ} 111$, de 20/11/2003), comunidades indígenas e pescadores artesanais." (VIANA, C. A. S. \& VIEGAS, G. L. PAA: Evolução das Operações. Disponível em $<$ www.conab.gov.br> Acesso em 20/12/2010)
} 
tradições, teoricamente, apenas se se mantiver de alguma forma fiel a suas características culturais "genuínas". Daí a convergência com a idéia de preservação do patrimônio cultural, subjacente às políticas de garantia de direitos às comunidades tradicionais, incluindo os remanescentes de quilombo e até mesmo os povos indígenas.

A idealização da tradição impede a percepção da dinâmica que caracteriza os modos de vida tradicionais em seus ajustes freqüentes às novas situações em que as comunidades são submetidas no processo histórico. Além disso, dificulta o entendimento de que tais comunidades são parte do jogo de forças político em torno das questões agrárias e ambientais (dentre outras), não estando apartadas desses campos de luta.

Quando associada à necessidade de conservação da natureza, essa leitura da cultura, que não contempla as transformações a que estão sujeitas as tradições, apresenta convergência com a idéia de conservação do patrimônio cultural. Assim, a concepção idealizada e reducionista da tradição das comunidades camponesas tem sido privilegiada no estabelecimento das políticas ambientais, já que se entende que para conservar a natureza é preciso preservar as comunidades tradicionais.

O empobrecimento da noção de tradição e a própria defesa da conservação da natureza com base em práticas estranhas às da comunidade resultam na adequação da "tradição" às exigências da conservação ambiental. A adoção de técnicas agroecológicas, nesse contexto, indica o que é prioritário de ser preservado.

Essa apreensão reducionista da tradição poderia ser considerada como uma das sementes dos conflitos que surgem a partir do estabelecimento das políticas de reconhecimento do direito de acesso a terra e da realização prática dos instrumentos de (re)organização dos territórios dessas comunidades tradicionais.

A consideração da dimensão simbólica e sua relação dialética com as novas situações ao longo da história da comunidade poderá contribuir para pensarmos a tradição de uma forma que não seja estática. E nesse caminho seria de suma importância o envolvimento e a contribuição mais efetiva de geógrafos, antropólogos e sociólogos na realização de projetos de assentamento rural ou de projetos de desenvolvimento junto a essas comunidades.

Além disso, queremos chamar a atenção para o fato de que as questões da tradição e da conservação do meio ambiente precisam ser consideradas sob uma ótica 
A problemática ambiental e seu ambíguo encontro com a luta pela terra: desafios na 83 aproximação entre modo de vida tradicional e conservação da natureza, pp. 63-84.

mais ampla. Devem ser analisadas dentro da discussão das formas de propriedade da terra e da natureza, ou seja: os limites ou não do uso da natureza estão relacionados com as questões da estrutura agrária brasileira e da luta pela terra da classe camponesa, da qual fazem parte tais comunidades tradicionais.

\section{Referências Bibliográficas}

BOURDIEU, P. O Desencantamento do Mundo: Estruturas econômicas e estruturas temporais. São Paulo: Perspectiva, 1979.

. O Poder Simbólico. Rio de Janeiro: Bertrand Brasil, 2007.

BERNINI, C. I. De posseiro a assentado: a reinvenção da comunidade do Guapiruvu na construção contraditória do assentamento agroambiental Alves, Teixeira e Pereira, Sete Barras-SP. 2009. 174 f. Dissertação (Mestrado em Geografia Humana) - Faculdade de Filosofia, Letras e Ciências Humanas, Universidade de São Paulo, São Paulo, 2009.

BRANDENBURG. A. Movimento agroecológico: trajetória, contradições e perspectivas. In Desenvolvimento e Meio Ambiente: Caminhos da agricultura agroecológica. Curitiba: Editora UFPR, n.6, 2002.

BRASIL. Presidência da República. Decreto $\mathbf{n}^{\mathbf{0}} \mathbf{6 . 0 4 0}$ de 7 de fevereiro de 2007. Disponível em $\quad<$ https://www.planalto.gov.br/ccivil03/ato20072010/2007/decreto/d6040.htm> Acesso em 22 de agosto de 2009.

CANDIDO, A. Os Parceiros do Rio Bonito: Estudo sobre o caipira paulista e a transformação dos seus meios de vida. 9. ed. São Paulo: Duas Cidades/34, 1954.

CMMAD (Comissão Mundial sobre o Meio Ambiente e Desenvolvimento). Nosso futuro comum. Rio de Janeiro: Fundação Getúlio Vargas, 1988.

DIEGUES, A. C. O mito moderno da natureza intocada. 5. ed. São Paulo: Hucitec/USP, 2004.

LENCIONI, S. Região e Geografia. São Paulo: EDUSP, 2003.

MARTINS, J. S. O Cativeiro da Terra. 6.ed. São Paulo: Hucitec, 1996. 
PETRONE, P. A Baixada do Ribeira: Estudo de Geografia Humana. 1961. Tese (Doutorado em Geografia Humana) - Departamento de Geografia, FFLCH/USP, São Paulo, 1961.

A Baixada do Ribeira: Estudo de Geografia Humana In Boletim n. 283, Geografia n. 14, FFLCH/USP, São Paulo, 1966.

. Notas sobre os Sistemas de Cultura na Baixada do Ribeira, SP. In Boletim

Paulista de Geografia, São Paulo, n. 39, p. 47-63, out. 1961.

PORTO-GONÇALVES, C. W. Os (Des)caminhos do Meio Ambiente. São Paulo: Contexto, 2000.

. Geo-Grafías. Movimientos sociales, nuevas territorialidades y sustentabilidad. México: Siglo XXI, 2001.

SILVA, S. Camburí, território de brancos, negros e índios no limite do consenso caiçara: transformações de uma população tradicional camponesa. 2004. Dissertação (Mestrado em Geografia) - Departamento de Geografia, FFLCH/USP, São Paulo, 2004.

QUEIROZ, M. I. P. Relatos Orais: do Indizível ao Dizível. In SIMSON, O. M. V. Experimentos com Histórias de Vida (Itália-Brasil). São Paulo: Vértice, 1988, p.14-43.

. Bairros Rurais Paulistas: dinâmica das relações bairro rural - cidade. São Paulo: Duas Cidades, 1973.

. Vale do Ribeira: pesquisas sociológicas. São Paulo: FFCL, 1969. 